\title{
O PENSAMENTO PEDAGÓGICO DA REGIÃO SUL: PESQUISANDO A RELACAOO ENTRE TRABALHO E EDƯCAÇÃO
}

\author{
PEDAGOGICAL THINKING FROM THE SOUTH OF BRAZIL: SEEKING THE \\ RELATION BETWEEN WORK AND EDUCATION
EL PENSAMIENTO PEDAGÓGICO DE LA REGIÓN SUR: INVESTIGANDO LA RELACIÓN ENTRE EL TRABAJO Y LA EDUCACIÓN

Acacia Zeneida Kuenzer ${ }^{*}$ acaciak4@gmail.com

\author{
REVISTA PEDAGÓGICA \\ Revista do Programa de Pós-graduação em Educação da Unochapecó | ISSN 1984-1566 \\ Universidade Comunitária da Região de Chapecó | Chapecó-SC, Brasil \\ Como referenciar este artigo: KUENZER, A. Z. O pensamento pedagógico da região sul: pesquisando a \\ relação entre trabalho e educação. Revista Pedagógica, Chapecó, v. 17, n. 36, p. 30-50, set./dez. 2015.
}

\begin{abstract}
RESUMO: Este texto reflete a minha trajetória de formação e de trabalho, registrando os resultados das pesquisas que tenho realizado desde os anos 80. Ele foi escrito por solicitação da Revista Pedagógica da UNOCHAPECÓ, com o objetivo de disponibilizar a produção teórica sobre a área de Trabalho e Educação dos intelectuais da Região Sul. O texto está organizado em três partes: a trajetória escolar, a formação em pesquisa e o trabalho, e os principais resultados do processo investigativo. Esta última parte, com o intuito de facilitar a sistematização, organiza os resultados em quatro eixos: a pedagogia da fábrica, o ensino médio e a educação profissional, a formação de professores e a articulação entre trabalho, cultura e educação. A partir dessa sistematização, os leitores interessados poderão acessar os textos completos, referenciados na bibliografia.
\end{abstract}

Palavras-chave: Trabalho e Educação. Ensino Médio. Educação Profissional. Formação de Professores.

ABSTRACT: This text looks back on my academic life and work, recording the results of studies I have conducted since the 1980 . It was written at the request of the Pedagogical Journal of Unochapecó to provide information on the theoretical production in the field of Work and Education of intellectuals from the south of Brazil. The text is in three parts: schooling, research and work, and the main results of the research process. For the purpose of systematization, the latter part is organized into four sections: teaching in the workplace, high school and professional education, teacher training and the articulation between work, culture and education. With this systematization, interested readers can access the complete texts referenced in the bibliography.

Keywords: Work and Education. High School. Professional Education. Teacher Training.

RESUMEN: Este texto refleja mi trayectoria de formación y trabajo, registrando los resultados de las investigaciones que tengo realizado desde los años 8o. El trabajo fue escrito por solicitación de la Revista Pedagógica de la UNOCHAPECÓ, con el objetivo de poner a disposición la producción teórica acercadel área de Trabajo y Educación de los intelectuales de la Región Sur. El texto está ordenado en tres partes: la trayectoria escolar, la formación en investigación y el trabajo, y los principales resultados del proceso investigativo. Esta última parte, con la intención de facilitar la sistematización, organiza los resultados en cuatro ejes: la pedagogía de la fábrica; la enseñanza secundaria y la educación profesional; la formación de profesores; y la articulación entre trabajo, cultura y educación. A partir de esta sistematización, los lectores interesados podrán acceder a los textos completos referenciados en la bibliografía.

Palabras clave: Trabajo y Educación. Enseñanza Secundaria. Educación Profesional. Formación de Profesores. 
* Doutorado em Educação pela PUC/SP, professora titular aposentada da Universidade Federal do Paraná, professora permanente da Universidade Feevale, Pesquisadora $1 \mathrm{~A}$ do CNPq.

\section{A ESCOLA PÚBLICA PARA UMA FILHA DE PROFESSOR: ONDE TUDO COMEÇOU}

Nasci em uma pequena cidade do interior do Paraná, Rio Negro, onde vivi até 19 anos, filha da mistura de duas etnias, como a maioria dos brasileiros; no meu caso, de descendentes de imigrantes. Meu pai, descendente de alemães e franceses. Minha mãe, filha de libaneses que migraram para o Brasil em 1906.

Meu pai, filho de pai bancário e mãe que trabalhava em casa; minha mãe, a penúltima de 11 filhos de meus avós libaneses, que se radicaram em Morretes, no litoral do Paraná, todos criados em uma grande fazenda, com a ajuda de babás negras, ex-escravas ou filhas de ex-escravos. Meu avó, João Barberi, fez fortuna produzindo e exportando bananas e arroz. Mais tarde radicou-se em Curitiba e dedicou-se a importar carros, até que montou a primeira fábrica de tratores no Paraná, esforço pioneiro que foi encerrado a partir da competição predatória levada a efeito por uma das famílias de coronéis que dominavam a política paranaense nos anos 50. Depois do seu falecimento, em 1954, os filhos homens puseram toda a fortuna a perder, como era comum acontecer com as empresas familiares.

Pertenceu, minha mãe, à grande burguesia curitibana; nos anos 50 tinha automóvel, jogava com meu avô no Cassino do Ahu, estudava inglês, e, ao contrário das mulheres de sua época, cursava Química na Universidade Federal do Paraná. Era uma mulher elegante e culta, além de belíssima! Independente e nem um pouco conservadora, ao contrário da maioria das mulheres dessa época; sempre acompanhou as mudanças e esteve à frente de seu tempo. Talvez pela convivência na fazenda, com empregados ex-escravos, desenvolveu um forte senso de justiça e de compromisso com os pobres e com os trabalhadores, apesar de sua vida burguesa.

Quando conheceu meu pai, em 1947, ele cursava Farmácia na Universidade Federal do Paraná, após seu retorno da Itália, onde lutou, junto com seus companheiros da Força Expedicionária Brasileira, na Segunda Guerra Mundial; fez 19 anos no campo de batalha, amadurecendo em meio à destruição e ao sofrimento dos civis e dos militares. Como minha mãe, embora por caminho diverso, forjou sua identidade nos compromissos com a verdade, com a justiça, com a igualdade.

Deles eu nasci, filha única; cresci vivenciando esses valores, em que pese meu pai ter sido filiado à UDN, partido que representava os interesses da burguesia internacional; ele nunca foi de esquerda, mas foi um grande liberal.

Até meus 5 anos passava muitas horas com ele no laboratório de análises clínicas, especialidade facultada pelo curso de Farmácia à época, entre lâminas, microscópios, vidrarias, bancadas, banquetas.... e sapos! Para fazer os exames de gravidez, os únicos disponíveis à época. Vem dessa experiência minha curiosidade investigativa. 
E, como complemento, a farmácia!!!! Gavetinhas, prateleiras, tudo organizado... e classificado!

O seu rigor era contrabalançado pela doçura da minha mãe; cresci em meio às contradições de uma formação de classes burguesa e trabalhadora. "As pessoas valem pelo que são, e não pelo que aparentam”, dizia meu pai. Ao que minha mãe retrucava: "o que não justifica descuido com a aparência, pois a sociedade julga primeiro pelo que vê, e depois pelo que conhece!" "Há que sempre dizer a verdade", dizia meu pai; "mas a distância entre dizer a verdade e a falta de educação é muito tênue," dizia minha mãe! 'Se você não tem coisas agradáveis para dizer, cale-se!” E assim ia a vida. Mas quando se tratava de justiça, caráter, honestidade, compromisso com os mais pobres, não havia discordância.

Iluminados por suas crenças me deram dois irmãos adotivos, a partir dos meus 10 anos. A concepção de família ampliada sempre foi muito natural em nossa casa.

Meu pai, a partir de 1955, foi se apaixonando pela docência e abandonou o laboratório e a farmácia.

Assim, fui criada com salário de pai professor, que trabalhava 3 turnos para nos assegurar vida digna, mas nem um pouco fácil.

Sempre cursei a escola pública, onde vivi ricas experiências interclasse; com muita qualidade, a escola pública agregava desde os filhos dos profissionais liberais aos filhos dos trabalhadores. Foi na escola pública que desenvolvi meu senso de solidariedade e de acolhimento das diferenças.

Desde cedo aprendi a decidir e a resolver meus problemas; exercer autonomia foi um traço muito forte de minha educação, a partir dos valores paternos... junto com uma boa dose de obstinação e teimosia quando se tratava de verdade, respeito e justiça.

Foi essa trajetória que lançou as raízes para minhas opções epistemológicas futuras.

\section{A FORMAÇÃO PROFISSIONAL E O TRABALHO}

Filha de pai professor tive que estudar muito, desde muito cedo, o que, para mim, sempre foi natural, dada a minha história. No ensino médio, por pura teimosia, cursei a escola normal, que formava professoras primárias (para atuar nas séries iniciais do ensino fundamental), e o curso científico, que preparava para o vestibular. Isso porque meu pai não abria mão de uma formação profissional antecipada - para a eventualidade de ter que trabalhar (caso meu futuro marido não pudesse me sustentar), e eu queria cursar medicina. Ganhei bolsa de estudos de um cursinho pré-vestibular e me preparei para morar em Curitiba. Contudo, uma das minhas melhores amigas da Escola Normal, que sempre sentava atrás da minha carteira nos dias de prova, me pediu para fazer o vestibular de Pedagogia junto com ela, na Universidade Católica do Paraná; fui, e passei em $5 .^{\circ}$ lugar com minha formação de normalista feita no 
interior; e minha amiga não foi aprovada. Comecei a fazer o curso só para ver como era, e descobri que eu gostava mesmo era de ciências humanas, principalmente da filosofia. Aos poucos fui me apropriando e me apaixonando pela ciência da educação e desisti da medicina.

No quarto ano de Pedagogia, em 1972, a professora Maria Dativa de Salles Gonçalves, minha professora e grande amiga, uma das mulheres mais importantes da minha vida, que havia militado nos movimentos da juventude católica e na época ministrava Administração Escolar e Estrutura e Funcionamento de Ensino, foi aos poucos me inserindo na docência no ensino superior, na própria Universidade Católica; assim foi que a substituí quando grávida de seu primeiro filho, e depois de formada, fui contratada como sua assistente, na própria Universidade Católica do Paraná. Assim, comecei minha carreira, no ensino superior, nos anos difíceis que sucederam o golpe militar. Vinda do interior, não tinha nenhuma formação política; a na Universidade, não se podia sequer falar de realidade brasileira; tanto que aprendi muito bem, com a Maria Dativa, a teoria geral dos sistemas...

Nesse período ministrei aulas na Escola Normal Margarida Kirchner e na recém-criada FUNORTE, hoje Universidade do Contestado em Rio Negro e Mafra, me dividindo entre as minhas duas cidades e Curitiba, até casar, em 1973, e me mudar para Cascavel, no Paraná. Lá, fiquei um semestre sem trabalhar, até que a FECIVEL, que deu origem à UNIOESTE, chegou ao terceiro ano de funcionamento, quando a Didática passou a ser ofertada para as licenciaturas, e fui contratada. Contudo, não me adaptei à cultura da cidade, em pleno processo de constituição nos anos 70; não havia sequer uma livraria. Foi então que decidi fazer mestrado, e convenci meu marido a fazer o mesmo.

Assim como cursar Pedagogia não havia sido fruto de uma decisão consciente, a decisão de cursar o mestrado atendeu antes ao meu desejo de sair de Cascavel do que a uma necessidade acadêmica, embora ela estivesse no horizonte, mas em segundo plano. Como gostava muito de Administração Escolar, e à época havia um curso avaliado como A pela Capes na PUC do Rio Grande do Sul, lá fui eu; com bolsa da Capes, e com o apoio da Professora Maria Estela Dal Pai Franco, outra mulher que foi muito importante na minha vida, da qual tive o privilégio de me tornar amiga. Em Porto Alegre, em 1979, três meses antes da defesa da dissertação, nasceu Liz Cláudia, minha filha querida, com quem muito tenho aprendido ao longo dos anos. Nessa época, a amizade o acolhimento e o apoio das professoras Maria Estela e Délcia Enricone foram decisivos para que eu cumprisse meus compromissos acadêmicos, concluindo a dissertação, e iniciasse minha trajetória de mãe, tarefa nada fácil para quem estava distante da família.

Estudei muito no mestrado, principalmente os clássicos e contemporâneos da Teoria geral da Administração, Metodologia de Pesquisa e Estatística; esses estudos foram 
fundamentais para a etapa seguinte, a partir do doutorado, onde iniciei minha trajetória na área de Trabalho e Educação.

Minha introdução nas teorias críticas teve seu início de uma forma peculiar: com os estudos da crítica à burocracia e ao estado patrimonialista, nas aulas de Ciência Política, no mestrado, com o professor Fernando Coutinho Garcia; e, já na fase da pesquisa de campo na construção da dissertação, com as orientações do professor José Vicente Tavares dos Santos, que ministrava Sociologia do Trabalho na PUC/RS.

A dissertação tinha como objeto a formação de recursos humanos de nível intermediário; foi um trabalho bem diferente das dissertações do Programa à época, e só foi possível graças ao apoio do Professor Sebastião Campos, que acolheu a proposta e me conferiu autonomia para realizá-la. Foi a minha primeira tentativa de articular política, economia e trabalho; contudo, embora eu tivesse feito pesquisa de campo nas escolas de formação de técnicos de nível médio para as áreas de calçado e pedras semipreciosas nas escolas do SENAI no Rio Grande do Sul, os resultados foram limitados, porque parti das categorias mais abstratas para a materialidade. Ou seja, estava com a dialética de cabeça para baixo.

O mestrado foi muito importante para a minha trajetória futura: lá estudei os clássicos da administração e me aprofundei na metodologia de pesquisa, que já incluía, à época, as metodologias qualitativas, embora ainda de forma incipiente.

Em julho de 1979 retornei a Curitiba com o desafio de retomar as atividades profissionais, desta vez na Universidade Federal do Paraná, no Setor de Educação, quando era Diretora a professora Zélia Mileo Pavão, que imediatamente me acolheu como professora visitante. Reencontrei a Dativa e fiz novos amigos, passando a integrar o grupo de professores de esquerda do Departamento de Planejamento e Administração Escolar: Alfeu Marques Garcia, Evaldo Montiani Ferreira, Naura Syria Carapeto Ferreira, Odilon Carlos Nunes. À época, Dativa, Naura, Evaldo e Alfeu cursavam o Mestrado em Educação no referido Setor, e, com minha formação e experiência em pesquisa na PUC/RS, embora ainda incipientes, tive a felicidade de poder auxiliá-los em suas dissertações. Fiz concurso e fui contratada como efetiva.

Em 1981 iniciei o doutorado em História, Política e Sociedade na PUC/SP, coordenado pelo Dr. Dermeval Saviani, que foi meu orientador. Assim como a decisão de cursar o mestrado, buscar o doutorado não foi uma opção política em primeiro plano, mas sim a busca por algo diferente e prazeroso que me permitisse conservar o casamento, que havia se desgastado bastante no transcurso do mestrado; como sempre digo para os meus alunos, as opções epistemológicas sempre trazem consequências em nossa forma de encarar e viver a vida; embora eu tivesse 
feito apenas um contato inicial com as teorias críticas lendo alguns poucos textos clássicos, foi o suficiente para criticar minhas opções anteriores, rever meus valores e buscar novos caminhos. Cursar o doutorado foi a travessia.

Ainda lembro o espanto do professor Dermeval quando, em uma das nossas inúmeras conversas, narrei a ele as razões que me levaram ao doutorado. A decisão pela PUC/SP não foi acidental, para o que meus companheiros de Departamento muito influíram, principalmente a Dativa, que já tinha experiências anteriores na esquerda. Fui aprovada com um projeto que articulava trabalho e educação, mas ainda com a dialética de cabeça para baixo. Com o avanço dos estudos no campo do materialismo histórico, fui aprendendo que o caminho da produção do conhecimento partia da materialidade, e não das ideias; adentrei as leituras neste campo e finalmente me defini epistemologicamente, sintetizando a trajetória anterior. Para isso contribuíram os melhores professores eu poderia ter: Dermeval, Otávio Ianni, Paulo Freire.

Ao final do primeiro ano do curso, a partir do aprofundamento epistemológico, radicalizaram-se as opções de vida; decidi trilhar meu próprio caminho, com minha filha, então com três anos de idade.

Em março de 1984, defendi a tese, que deu origem ao livro Pedagogia da Fábrica, título dado pelo Dr. Otávio Ianni, membro da banca; naquela época havia tão poucos doutores, que à medida que nos titulávamos, participávamos das bancas uns dos outros. Assim, Gaudêncio Frigotto, titulado um pouco antes, estreou na minha banca.

Em 1985, graças ao esforço da Professora Julieta Calazans, então representante da área de Educação na Capes, passei a integrar o corpo docente do Mestrado em Educação, junto com a professora Sônia Kenski, que havia concluído seu doutorado na Alemanha. E desde então, as tarefas de docência, orientação e pesquisa têm sido o meu trabalho.

Em 1986 passei a integrar a gestão na área pública; com a eleição do Tancredo, os atores do processo de democratização passaram a integrar o poder; e faltavam quadros. Assim é que o Dr. Jaques Veloso, então no MEC, fez a mim o convite para assumir uma coordenação no CNPq, para estruturar a área de Educação e Trabalho; embora inexperiente, aceitei, me afastei da UFPR e fui para Brasília.

Para iniciar a organização da área promovi uma reunião de aproximadamente 30 intelectuais que pesquisavam educação e trabalho, para que definíssemos uma pauta de investigação que orientaria os apoios financeiros a serem concedidos pelo CNPq. Foi nessa reunião que Miguel Arroyo argumentou que a área devia se denominar Trabalho e Educação, e não ao contrário, demarcando a opção epistemológica do grupo ao indicar que é a materialidade das relações de produção e sociais que definem a educação, e não o inverso. A partir dessa pauta, o trabalho do GT 09 da ANPED se estruturou, conferindo organicidade às 
nossas investigações; essa pauta construída coletivamente nos orientou por muitos anos, e ainda continua a orientar alguns de nós, com os ajustes que a dinâmica do capital passou a exigir. Nos anos seguintes, quando fui Diretora do Setor de Educação e com apoio do CNPq, pude promover vários encontros dos pesquisadores da área para intercâmbio de experiências, em que essa pauta continuou a nos orientar, e este foi um tempo muito rico para o desenvolvimento do grupo.

A experiência em gestão, no CNPq, seguida pelo INEP e MEC até 1989, fez com que o primeiro reitor eleito da UFPR, Riad Salamuni, no meio de uma crise política, trocasse 3 Pró-reitores; fui convocada a voltar e assumir a Pró-reitoria de Planejamento, Orçamento e Finanças por dois anos, em vista da experiência adquirida em Brasília. Em seguida, eleito o reitor Carlos Faraco, assumi por quatro anos a Pró-reitoria de Recursos Humanos e Assuntos Estudantis. Fui eleita diretora do Setor de Educação por duas gestões, atuando por oito anos. Ao todo, foram 16 anos de gestão pública, o que representou para mim um verdadeiro pós-doutorado em gestão pública.

Essa experiência foi ancorada nos meus estudos de mestrado e doutorado, de caráter indisciplinar, em que a articulação entre administração, educação e trabalho foi a razão da minha saudável sobrevivência nesses 16 anos. Em que pese os compromissos com a gestão, sempre ministrei aulas na graduação, na pós-graduação, orientei, pesquisei e publiquei, por entender que essa era minha responsabilidade como docente de ensino superior.

Ao final da década de 90 fiz concurso para professora titular na UFPR, o que implicava em tese original, prova escrita com leitura oral e prova didática, tendo sido aprovada.

A partir de 2000 passei a participar dos Comitês de Avaliação da CAPES na área de Educação, e nos últimos anos, na área interdisciplinar, bem como no Comitê da área de Educação do $\mathrm{CNPq}$, experiências que foram muito enriquecedoras. Foi no Comitê da CAPES que conheci e passei a trabalhar com quem seria uma grande amiga e parceira: Maria Célia Marcondes Moraes, que deixou uma grande lacuna entre nós. Com ela fizemos muitos estudos e propostas sobre os critérios de avaliação e sobre a produção dos Programas de Pós-graduação em Educação; criticamos as categorias pós-modernas que já se introduziam na pesquisa em educação e na formação de professores; com ela, muito aprendi.

Em 2006 me aposentei da UFPR; dediquei-me à pesquisa e à consultoria a partir desse ano, mantendo-me como professora voluntária do Programa de Pós-graduação em Educação, ministrando aulas e orientando até 2014; em dezembro de 2012 passei a integrar o Programa de Doutorado em Diversidade e Inclusão Social da Universidade Feevale, em Novo Hamburgo, onde continuo atuando.

A partir de 2006, entrei em contato com as escolas que formam juízes do trabalho, convidada pelos magistrados 
Leonardo Wandelli e Graça Freitas; essas escolas demandavam a elaboração e implementação de projetos pedagógicos para capacitar juízes e servidores; pela minha experiência nas relações entre trabalho e educação, a aproximação com essas, e com as escolas das demais áreas da Justiça, tem sido muito profícua, por disponibilizar um fértil campo de pesquisa em educação profissional.

Foram muitos os amigos, orientandos e alunos com os quais construí minha trajetória desde o início da década de 70; impossível listar aqui todos os que, de alguma forma, contribuíram para a minha formação. Fica o registro do importante papel que todos desempenharam na minha caminhada...

\section{A PRODUÇÃO ACADÊMICA: ESTUDANDO A RELAÇÃO ENTRE TRABALHO E EDUCAÇÃO}

\subsection{A Pedagogia da Fábrica: a fase da investigação nas formas de organização tayloristas fordistas}

A produção acadêmica construída ao longo dessa trajetória tem seu marco inicial na Pedagogia da Fábrica, a tese de doutorado defendida em março de 1974 e orientada pelo Dr. Dermeval Saviani, cuja pesquisa de campo foi realizada em uma empresa automobilística da Cidade Industrial de Curitiba, fundamentada nas categorias do materialismo histórico (KUENZER, 1985). A Ideologia Alemã (MARX; ENGELS, 2006), O Capital (MARX, 1982) e os textos de Gramsci, em particular o Americanismo e Fordis$m o$ (GRAMSCI, 1980), foram as principais referências para a análise das dimensões pedagógicas das relações sociais e produtivas que se desenvolvem na fábrica capitalista. Em que pese o esforço para analisar os dados das entrevistas nas dimensões interna e externa à fábrica, a pouca experiência teórico/prática resultou em limites na análise das categorias hegemonia e contradição, fato apontado pelo Dr. Ianni já na banca. Apreender toda a riqueza das inúmeras mediações possíveis exigia mais fôlego teórico do que minha incipiente experiência acadêmica poderia realizar. Há que considerar, contudo, embora sem a pretensão de justificar os limites daquele trabalho, que não havia estudos à época que analisassem o mundo do trabalho a partir da educação; as pesquisas disponíveis na perspectiva crítica eram da área da Sociologia do Trabalho.

Apesar dos limites, a Pedagogia da Fábrica trouxe contribuições que permitiram desenvolver uma linha investigativa que permitiu avançar na compreensão das relações entre trabalho e educação no âmbito do taylorismo/ fordismo e do toyotismo. Nesse trabalho, merece destaque a apreensão e sistematização das relações ampla e especificamente pedagógicas das relações sociais e produtivas que articulam trabalho e escolarização/formação profissional.

No âmbito dos processos amplamente pedagógicos foi possível descrever e analisar os mecanismos de controle, 
de apropriação e de distribuição desigual dos conhecimentos dos e aos trabalhadores; as estratégias ideológicas levadas a efeito por gestores e assistente social para esvaziar as estratégias de organização dos trabalhadores; as contradições entre as políticas de benefícios diretos e indiretos, que realmente se diferenciavam positivamente das desenvolvidas por outras plantas produtivas, e as estratégias de subsunção dos trabalhadores.

Do ponto de vista dos processos especificamente pedagógicos, a Pedagogia da Fábrica abriu caminho para um segundo grupo de pesquisas realizadas pelo grupo que constituiu o Núcleo de Pesquisas em Reestruturação Produtiva e Educação - NERE/UFPR, envolvendo pesquisadores de outras áreas na UFPR e da hoje Universidade Federal Tecnológica do Paraná-UTFPR, então CEFET/PR, em 3 plantas produtivas da indústria branca e eletroeletrônica situadas em Curitiba e Região Metropolitana. A opção foi por pesquisar empresas que passavam pelo processo de reestruturação produtiva, compreendidas como síntese do movimento de organização do capital naquele período, em que a crise de acumulação já se anunciava fortemente. A própria planta que foi objeto de pesquisa na Pedagogia da Fábrica expressava a transição para outro momento do processo de acumulação, uma vez que integrava, no início dos anos 8o, as experiências de organização e gestão do trabalho mais avançadas realizadas na Suécia, e ainda não incorporadas pela indústria automobilística brasileira.

Como tudo na minha trajetória acadêmica, essa empresa não foi uma escolha intencional, e sim a empresa que abriu suas portas à pesquisa; puro acaso! Hoje me dou conta de como foi decisivo esse fato para minha trajetória investigativa futura: aquela empresa anunciava as mudanças que estavam por vir, no novo regime de acumulação, com, no mínimo, uma década de antecedência!

Esse segundo momento da trajetória investigativa, orientado pela questão "onde e como os trabalhadores aprendem o trabalho", permitiu delimitar o conhecimento tácito como dominante nos processos de base eletromecânica e organizados segundo o paradigma taylorista/fordista. Foram sistematizadas as categorias da pedagogia taylorista/fordista que articulam os processos ampla e especificamente pedagógicos: a memorização de procedimentos por repetição, como processo pedagógico dominante; o professor como protagonista, o aluno como receptor passivo e os conteúdos como verdades inquestionáveis; a teoria separada da prática, a autonomização da parte como expressão da especialização e da fragmentação do conhecimento, a primazia do conhecimento tácito sobre o científico. A Pedagogia que vinha da fábrica visava o desenvolvimento da competência no fragmento e materializava a distribuição desigual do saber como estratégia de realização da acumulação do capital.

As conclusões dessa etapa da trajetória investigativa foram sistematizadas em um capítulo de livro organizado 
por Saviani, Sanfelice e Lombardi, em 2005 (KUENZER, 2005 a), onde se tratou da relação dialética que ocorre entre os processos de exclusão includente, na ponta do mercado, e a inclusão excludente na ponta da escola, como a nova forma de manifestação da dualidade estrutural no regime de acumulação flexível, pela integração dos processos produtivos.

Essa relação foi assim sistematizada: do ponto de vista do mercado, o processo que pode ser caracterizado como exclusão includente, que corresponde à expulsão de trabalhadores do trabalho formal para reincorporá-los, nas plantas e nas cadeias produtivas mediante formas precárias de contratação e subcontratação, que vão da terceirização ao trabalho similar ao trabalho escravo e ao trabalho infantil. É importante destacar que esta é a lógica das novas relações entre capital e trabalho em tempos de mundialização do capital e reestruturação produtiva, viabilizadas por Estados de tipo neoliberal. Não se trata, portanto, de mera disfunção de efeitos passageiros, mas da própria possibilidade de acumulação do capital, posto que a reestruturação produtiva se alimenta e mais se dinamiza quanto mais produz o seu contrário: o trabalho precarizado.

À exclusão includente corresponde outra lógica, equivalente e em direção contrária, do ponto de vista da educação, ou seja, a ela dialeticamente relacionada: a inclusão excludente, ou seja, as estratégias de inclusão nos diversos níveis e modalidades da educação escolar aos quais não correspondam os necessários padrões de qualidade que permitam a formação de identidades autônomas intelectual e eticamente capazes de responder e superar as demandas do capitalismo. Estas estratégias, de modo geral, referem-se às diferentes formas de certificação mediante processos pedagógicos aligeirados e simplificados, que não conferem rigor e seriedade à educação geral e à formação profissional. Assim, através dos processos de inclusão excludente, a educação escolar e não escolar se articula dialeticamente aos processos de exclusão includente existentes no mundo do trabalho, fornecendo ao capital a força de trabalho disciplinada técnica e socialmente para atender as necessidades do processo de acumulação.

A expressão pedagógica deste princípio tem se dado através da pedagogia das competências com suas categorias, que já havia sido objeto de análise crítica em dois artigos publicados no Boletim Técnico do SENAC, em 2002 e 2003 (KUENZER, 2002 e 2003).

\subsubsection{A Pedagogia da Fábrica: a fase da investigação no regime de acumulação flexível}

As pesquisas realizadas em plantas produtivas reestruturadas não se mostravam suficientes para compreender as relações entre as mudanças ocorridas no mundo do trabalho decorrentes da constituição do processo de acumulação flexível e a nova realidade da educação. 
Dadas as características desse regime de acumulação, em particular a integração produtiva, identificou-se a necessidade de pesquisar como se dava o processo de exclusão includente em uma cadeia produtiva, para que se pudesse sistematizar, pelo menos em caráter preliminar, as categorias que articulam trabalho e educação na acumulação flexível. Para tanto, selecionou-se como objeto de investigação a cadeia do couro e calçado, que concentra todas as suas etapas no Vale do Rio dos Sinos; essa pesquisa teve o inestimável apoio da Universidade Feevale, localizada em Novo Hamburgo, e o financiamento do CNPq.

A hipótese que orientou a pesquisa é que o regime de acumulação flexível, ao aprofundar as diferenças de classe, aprofunda a dualidade estrutural, como expressão cada vez mais contemporânea, da polarização das competências. Em decorrência, o Estado exerce suas funções relativas ao financiamento da educação a partir da concepção de "público não estatal", que supõe o repasse de parte das funções do Estado e, portanto, de recursos públicos para a sociedade civil, alegando sua maior competência para realizá-las.

A forma de materialização da dualidade estrutural no regime de acumulação flexível foi caracterizada a partir da pesquisa, como "dualidade negada", na medida em que o projeto pedagógico proposto não admite as diferenças de classe, negando a existência de diferentes percursos educacionais a partir de uma proposta que se pretende unitária.

Partiu-se do pressuposto de que são os trabalhadores que produzem os ganhos de produtividade através dos processos de intensificação e precarização que resultam em consumo predatório da força de trabalho mediante a combinação de processos de extração de mais valia relativa (uso intensivo de tecnologia) e absoluta (extensão da jornada de trabalho). Isto significa afirmar que a flexibilização do trabalho, categoria central no regime de acumulação flexível, longe de avançar no processo civilizatório do próprio capital, representa o seu esgotamento, destruindo os poucos direitos que a classe trabalhadora conquistou ao longo de suas lutas (FRIGOTTO, 2005, p. 69).

Esta combinação, princípio basilar do toyotismo, é a essência da flexilibização. Assim é que, para assegurar a competitividade e, portanto,, a margem de acumulação, as firmas buscam, ao longo das cadeias produtivas, a combinação ótima (nunca máxima, pois esta compromete o custo final do produto) entre investimento em ciência e tecnologia e consumo de trabalho humano. A estratégia, portanto, é o aumento de produtividade através da integração dos sistemas de produção, e não da mera implantação da automação; esta, quando adotada, é definida a partir das necessidades da integração. Na cadeia coureiro-calçadista pesquisada, esta estratégia é clara; não há automação que supere o baixo custo do trabalho que combina os ateliês (oficinas), o trabalho domiciliar feito pelas costureiras e a rede de trabalhadores manuais desqualificados que fazem os acabamentos, os trançados de couro, os bordados, 
a colocação das fivelas, enfim, o conjunto de atividades conhecidas como "enfiadinhos".

A integração dos sistemas de produção permite, através da subcontratação organizada, que sistemas mais antigos, como o trabalho domiciliar, familiar, artesanal e paternalista, deixem de ser marginais e assumam um novo papel, passando a ser orgânicos e, portanto, fundamentais ao processo de acumulação. Na cadeia estudada verificou-se, por exemplo, uma relação "paternal" entre o intermediário e os trabalhadores domiciliares, os quais, sem o seu apoio, não teriam como conseguir trabalho de forma tão continuada quanto permitem as oscilações de uma demanda marcada pela exportação.

Ou seja, relações de trabalho que se supunham superadas através do processo civilizatório do capital, retornam como estratégias essenciais ao processo de acumulação, combinadas com relações mais contemporâneas mediadas pela ciência e pela tecnologia, através da flexibilização.

No artigo que apresenta os resultados de quatro anos de pesquisa de campo, em que se fizeram inúmeras visitas, observações e entrevistas em todas as etapas da cadeia produtiva, são sistematizadas, embora ainda em forma de síntese provisória, as categorias da pedagogia do regime de acumulação flexível, apresentadas a seguir (KUENZER, 2007).

A primeira, e talvez a de maior poder explicativo, é a que se denominou " arranjos flexíveis de competências diferenciadas".

Diferentemente do que ocorria no taylorismo/fordismo, onde as competências eram desenvolvidas com foco em ocupações previamente definidas e relativamente estáveis, a integração produtiva se alimenta do consumo flexível de competências diferenciadas que se articulam ao longo das cadeias produtivas. Estas combinações não seguem modelos preestabelecidos, sendo definidas e redefinidas segundo as estratégias de contratação e subcontratação efetivadas para atender demandas puxadas pelo mercado de forma competitiva.

Os arranjos flexíveis, em substituição à polarização de competências clássica no taylorismo/fordismo, não podem ser compreendidos como mera oposição, rígida e formal, entre os que têm formação científico-tecnológica avançada, e por isso se incluem, e a grande massa de trabalhadores precariamente escolarizados, cuja força de trabalho é consumida predatoriamente em trabalhos desqualificados, ou é excluída.

São combinações que ora incluem, ora excluem, trabalhadores com diferentes qualificações, de modo a constituir corpos coletivos de trabalho dinâmicos, através de uma rede que integra diferentes formas de subcontratação e trabalho temporário que, ao combinar diferentes estratégias de extração de mais-valia, asseguram a realização da lógica da mercantil.

Se há combinação entre trabalhos desiguais e diferenciados ao longo das cadeias produtivas, há demandas 
diferenciadas, e desiguais, de qualificação dos trabalhadores; contudo, os arranjos são definidos pelo consumo da força de trabalho necessário, e não a partir da qualificação. O foco não é a qualificação em si, mas como ela se situa em dada cadeia produtiva, com o que ela se relativiza; a priori, não há como afirmar que certo trabalhador é ou não qualificado, uma vez que isto se define a partir de sua inclusão na cadeia; ou seja, a dimensão de relação social da qualificação se superlativiza na acumulação flexível, que avança na centralização do trabalho abstrato.

O que determina a inclusão na cadeia, portanto, não é a presença ou a ausência de qualificação, mas as demandas do processo produtivo, que combinam diferentes necessidades de ocupação da força de trabalho, a partir do trabalho necessário à realização da mercadoria.

Daí o caráter "flexível" da força de trabalho; importa menos a qualificação prévia do que a adaptabilidade, que inclui tanto as competências anteriormente desenvolvidas, cognitivas, práticas ou comportamentais, quanto a competência para aprender e para se submeter ao novo, o que supõe subjetividades disciplinadas que lidem adequadamente com a dinamicidade, com a instabilidade, com a fluidez.

A afirmação, portanto, da necessidade de elevação dos níveis de conhecimento e da capacidade de trabalhar intelectualmente, professada no discurso sobre a educação na acumulação flexível, mostra seu caráter concreto: a necessidade de ter disponível para consumo nas cadeias produtivas, força de trabalho com qualificações desiguais e diferenciadas, que combinadas em células, equipes, ou mesmo linhas, atendendo a diferentes formas de contratação, subcontratação e outros acordos precários, assegurem os níveis desejados de produtividade, através de processos de extração de mais-valia que combinam as dimensões relativa e absoluta.

A segunda categoria, portanto, que configura a dualidade na acumulação flexível é a ênfase na educação geral para a educação do trabalhador multitarefa; na perspectiva da acumulação flexível, a distribuição desigual e diferenciada do conhecimento que se dá diferentemente do que ocorria no taylorismo/fordismo, onde se valorizava o conhecimento tácito dos trabalhadores operacionais. $\mathrm{Na}$ acumulação flexível, a proposta é expandir a educação básica para os que vivem do trabalho, como condição para a formação flexível, o que permite o exercício de múltiplas tarefas no mesmo, ou em diferentes espaços de trabalho ao longo das cadeias produtivas. O conhecimento científico-tecnológico de alto nível, estratégico para a competitividade, continua reservado para os cientistas e técnicos que atentem às demandas do capital.

A estratégia através da qual o conhecimento é disponibilizado/negado segundo as necessidades desiguais e diferenciadas dos processos de trabalho integrados é o que temos chamado de inclusão excludente na ponta da escola. Ao invés da explícita negação das oportunidades de acesso 
à educação continuada e de qualidade, há uma aparente disponibilização das oportunidades educacionais, através de múltiplas modalidades e diferentes naturezas, que se caracterizam por seu caráter desigual e na maioria das vezes meramente certificatório, que não asseguram domínio de conhecimentos necessários ao desenvolvimento de competências cognitivas complexas vinculadas à autonomia intelectual, ética e estética.

Desta forma, a relativização da qualificação com foco na ocupação permite a formação de um maior contingente de trabalhadores com mais educação, se possível básica completa e até superior, o que viabilizará maior flexibilidade no seu uso combinado ao longo das cadeias produtivas. Assim, caracteriza-se menor dependência do capital em relação ao trabalho qualificado, que, pelo uso flexível, fica mais vulnerável, principalmente pela precarização e pela instabilidade.

A terceira categoria que a pesquisa permitiu sistematizar foi a intelectualização das competências, do que resultam novos arranjos entre conhecimento científico e conhecimento tácito.

A relação entre o conhecimento tácito e o científico foi objeto de pesquisa em 2006, em uma balsa de construção civil de uma empresa petroquímica (KUENZER; ABREU; GOMES, 2007). Entre seus resultados, essa pesquisa mostrou que, no trabalho organizado segundo o paradigma taylorista/fordista, é o conhecimento tácito que torna possível a execução das tarefas em face das diferenças entre trabalho prescrito e trabalho real, em razão do que o capital permanece em significativa dependência do trabalho, a partir do que reforça o poder de negociação dos trabalhadores. Contudo, dependendo da complexidade do trabalho e das possibilidades de participação nas decisões, a relação entre os conhecimentos tácitos e científicos se diferencia.

Assim é que a realização de tarefas pouco complexas e a centralização das decisões no gestor contribuem para conferir primazia ao conhecimento tácito simplificado, que demanda conhecimento teórico também simplificado. Já a realização de tarefas complexas combinadas com processos decisórios participativos e com trabalho de equipe desenvolvem conhecimentos tácitos complexos, que se articulam a conhecimentos científicos obtidos na formação escolar e profissional mais avançada.

Na pesquisa foi possível concluir que o conhecimento tácito não desaparece com a implantação de novas tecnologias, em particular com as de base microeletrônica, mas muda de qualidade, passando a exigir maior aporte de conhecimentos científicos que não podem ser obtidos somente através da prática, senão através de formação sistematizada. Vista dessa forma, a relação entre conhecimento tácito e conhecimento científico na base microeletrônica não é de oposição e sim de articulação dialética, posto que são categorias que se integram nos processos de trabalho flexibilizados, nos quais a prevalência do tácito ou do 
científico responde à especificidade do trabalho a ser realizado por uma força de trabalho de qualificações diferenciadas que se articulam para atender às necessidades das cadeias produtivas.

\subsection{Ensino médio e educação profissional: políticas e propostas}

A produção acadêmica nessa área teve seu início em 1985, quando era Diretora do INEP/MEC a Dra. Vanilda Paiva, que tinha como Diretora de Pesquisa a Dra. Maria Umbelina Caiafa Salgado. Um dos programas dessa equipe era identificar pesquisadores de temas relevantes para a universalização da educação com qualidade. Esses pesquisadores eram reunidos no INEP, onde discutiam o estado da arte da pesquisa na área específica e elaboravam um programa investigativo que orientaria os financiamentos por aquela agência, alguns em parceria com a CAPES e CNPq; naquele período se iniciava o movimento de articulação entre as agências financeiras.

Em 1985 fui convidada para participar do grupo que discutia a pesquisa sobre ensino médio e educação profissional, campo até então sob a hegemonia dos economistas da educação, apoiados na teoria do capital humano; as abordagens críticas apenas se iniciavam, e a tese do Dr. Gaudêncio Frigotto, também formado na PUC/SP, A produtividade da escola improdutiva, foi o grande marco dessa fase.

Eu recebi a incumbência, pelo INEP, de estudar o estado da arte das pesquisas sobre o então ensino de $2 .^{\circ}$ grau e a educação profissional, que foi publicado pela Cortez (KUENZER, 1997a). O texto sistematizava as pesquisas que eram referências para a análise crítica das políticas e propostas para esse nível a partir da Lei 5692/71.

Em 1997 foi publicado, também pela Cortez, um estudo que fazia crítica às políticas do estado neoliberal para o ensino médio e para a educação profissional a partir do projeto de lei que tramitava no Congresso Nacional, onde tivemos intensa participação nos debates que antecederam o Decreto Lei 2208/97 (KUENZER, 1997b).

Intensificaram-se os debates sobre o ensino médio e a educação profissional com base nas categorias do materialismo histórico, em particular nos textos de Gramsci. A grande questão que se colocava era a necessária objetivação da crítica em propostas que respondessem às necessidades dos que vivem do trabalho. Foi nesse contexto que intelectuais progressistas que assumiram a Secretaria de Estado da Educação no Mato Grosso convidaram o nosso grupo de pesquisa da UFPR, integrado por pesquisadores das diferentes áreas do conhecimento, para construir coletivamente uma proposta para o ensino médio.

O resultado desse trabalho foi publicado em livro, em 2000, também pela Cortez (KUENZER, 2000). A descontinuidade política fez com que a implementação da proposta fosse interrompida por duas gestões, sendo retomada em 
2008, quando foram construídas as orientações por área de conhecimento das séries iniciais ao ensino médio, com docentes da rede pública, técnicos da SEDUC/MT e docentes da UFMT; as orientações foram publicadas e disponibilizadas para as escolas.

Em 2006, foi concluído e publicado o estudo das políticas de educação profissional do período compreendido entre 1995 e 2005, abrangendo o segundo governo do Presidente Fernando Henrique Cardoso e no governo do Presidente Luis Inácio Lula da Silva. Essas políticas foram confrontadas com as demandas da classe trabalhadora a partir das mudanças ocorridas no mundo do trabalho no regime de acumulação flexível (KUENZER, 2006).

$\mathrm{O}$ estudo mostrou que, nos dois períodos de governo analisados, a formação precarizada para trabalhadores precarizados foi o eixo das políticas de educação profissional; os programas foram implementados pela mesma estratégia - as parcerias entre o setor público e o setor privado, que expressam a concepção de ação pública não estatal.

Os programas implementados se caracterizaram pela desarticulação e pela fragmentação das ações a que deram origem, através de uma profusão de projetos similares espalhados por diferentes unidades gestoras, particularmente no Governo do Presidente Lula, que antes se caracterizaram como estratégias de repasse de recursos para instituições privadas do que ações efetivamente comprometidas com a formação profissional dos jovens da classe trabalhadora.

Embora o discurso que sustentava os programas fosse o da articulação entre educação básica e profissional, as práticas pedagógicas enfatizavam o desenvolvimento do conhecimento tácito, como expressão da nova epistemologia da prática.

As conclusões desse estudo publicado pela Revista Educação e Sociedade mantém seu poder explicativo para os programas atuais de educação profissional, em particular para o PRONATEC, que por essa mesma razão não se constituiu em objeto de pesquisa nessa minha trajetória.

Em 2010, por demanda da Revista Educação e Sociedade, publiquei um artigo com a finalidade de subsidiar as discussões do Plano Nacional de Educação. Nesse texto, são analisados os dados referentes ao acesso e à qualidade do Ensino Médio no âmbito do PNE 2001/2010, que evidenciam a estagnação ocorrida na década e a inversão da dualidade estrutural, mediante a desqualificação da oferta de ensino médio de educação geral para os que vivem do trabalho.

Os dados relativos ao acesso, permanência e sucesso no ensino médio apontam que a oferta é majoritariamente branca e urbana, indicadores que não variaram significativamente no período, como também as taxas de acesso, aprovação, evasão e repetência. Os estudos sobre a relação entre escolaridade e inserção no mundo do trabalho mostraram que, no período estudado, embora a escolaridade 
tenha se ampliado entre os jovens, isso não significou ampliação das taxas de acesso ao emprego.

Esses dados confirmaram a hipótese que havia orientado o estudo: se a modalidade disponível para os jovens trabalhadores é o ensino médio de educação geral, preferencialmente noturno, de fato passa a ser essa "a escola para os filhos dos outros", revestida antes de caráter certificatório do que da qualidade social necessária para favorecer uma inclusão menos subordinada. Ou, quando a burguesia "disponibiliza" a versão média de educação geral para os trabalhadores, o faz pela via da oferta precarizada, que já não é mais necessária para assegurar sua hegemonia. Esta, em tempos de novas tecnologias de base microeletrônica, é assegurada pelo conhecimento científico-tecnológico, que passa a ser propriedade do capital e cuja distribuição é controlada. A esse fenômeno denominei dualidade invertida (KUENZER, 2010).

\subsection{A formação de professores}

A partir das categorias de análise estudadas ao longo dessa trajetória, e dos resultados obtidos com as pesquisas já relatadas, outro eixo investigativo foi sendo desenvolvido concomitantemente, por fazer parte do mesmo contexto analítico: a formação de professores no âmbito das mudanças ocorridas no mundo do trabalho e em relação com as políticas públicas de educação para a classe trabalhadora.

Merece destaque o artigo publicado em 1999 pela Revista Educação e Sociedade, que, ao analisar as políticas de formação de professores, concluiu que elas serviam à formação do "professor sobrante": formado precariamente, com baixos salários e condições de trabalho insuficientes, para trabalhar com os filhos da classe trabalhadora. Até porque, para atuar no ensino superior e nas instituições que educam os filhos da burguesia, eram outros os critérios de seleção, assim como as trajetórias de formação (KUENZER, 1999).

A partir de 2004 foram escritos os textos que criticavam as propostas de formação dos professores fundamentadas na epistemologia da prática; eram as primeiras críticas às propostas pós-modernas que já vinham sendo adotadas à época, em oposição às teorias da modernidade, e em particular ao materialismo histórico no campo da educação. Dois textos se destacam sobre essa temática; o elaborado para apresentação no ENDIPE, posteriormente publicado (KUENZER, 2005), e o produzido com a Dra. Maria Célia Marcondes Moraes, que tomava como objeto as produções dos Programas de Pós-graduação em Educação (KUENZER; MORAES, 2005b).

Os estudos sobre as relações entre trabalho e educação também subsidiaram estudos sobre o caráter capitalista do trabalho do professor e o consequente sofrimento no trabalho; com a Dra. Andrea Caldas, a partir de sua tese de doutorado, publicamos um capítulo de livro que analisou o trabalho do professor na perspectiva da desistência 
e da resistência, dimensões compreendidas não como em oposição, mas como a dupla face de uma relação dialética que acompanha o trajetória do professor (KUENZER; CALDAS, 2009).

\subsection{Propostas pedagógicas de integração entre cultura, trabalho e educação}

Todo o percurso investigativo aqui sinteticamente narrado teve a categoria trabalho como princípio educativo como fio condutor, pondo foco na relação entre trabalho, educação e cultura. Em que pese essa relação ter sido objeto de estudo de muitos pesquisadores, em particular dos que constituem o GT Trabalho e Educação da ANPED, a transposição dessa discussão teórica para a prática pedagógica é ainda um desafio a enfrentar.

Com o objetivo de avançar nessa questão, e dar uma resposta às escolas de educação profissional, estou desenvolvendo pesquisas experimentais para desenvolver práticas pedagógicas que permitam a integração, a partir da concepção de politecnia. Os campos de pesquisa foram definidos em espaços de educação profissional em duas áreas: em indústria do ramo petroquímico, entre 2008 e 2014, e nas Escolas Judiciais dos Tribunais Regionais do Trabalho e do Tribunal Regional Federal da $4^{\mathrm{a}}$ Região. Anteriormente haviam sido feitas tentativas de desenvolver essa pesquisa em escolas de formação profissional da rede pública, mas sem sucesso, em face da resistência a experimentar novas práticas.

A pesquisa tem por objeto o desenvolvimento, implementação, acompanhamento e sistematização dos processos de formação de profissionais mediante tutoria. Estes projetos permitiram desenvolver metodologia que integra trabalho, ciência e cultura em processos de alternância. Os resultados alcançados mostraram, contudo, que essa integração só se dá plenamente no espaço laboral, o que explica a dificuldade de implementá-la nas escolas, onde, no limite, é possível a integração a partir das áreas de conhecimento, mediante práticas interdisciplinares, que superam apenas em parte a fragmentação disciplinar e sua relação com as práticas social e de trabalho. A conclusão que a integração plena só é possível nas práticas social e de trabalho pela alternância, em processos transdisciplinares, leva a questionar as possibilidades reais de objetivação da educação profissional integrada ao ensino médio tal como foi proposta nas diretrizes curriculares nacionais.

Sobre esse objeto, ainda há muito a pesquisar; apesar do estudo já se desenvolver há mais tempo, as conclusões ainda são preliminares e precisam ser sistematizadas e experimentadas nas escolas, o que me mobiliza neste momento de minha trajetória. 


\section{CONCLUINDO: NOVAS PERSPECTIVAS, VELHAS UTOPIAS}

A preocupação que tem mobilizado meus estudos atualmente, constituindo-se em um projeto a ser desenvolvido, é o avanço da concepção pós-moderna no campo da educação, cujas categorias, tais como o individualismo, a competitividade, o hedonismo, o presentismo, a fragmentação ao substituir a solidariedade, o trabalho coletivo, os projetos de futuro, a universalidade, anunciam e já materializam paradigmas que negam a possiblidade do conhecimento e estabelecem relações sociais e de trabalho que, embora professem o contrário, superlativizam a lógica mercantil, a submissão da cultura à economia, a negação do trabalho, a estetização da ética, a negação da universalidade dos direitos e das desigualdades. Essas dimensões, que constituem a ética da acumulação flexível, anunciam uma sociedade onde viver o presente segundo os desejos individuais justifica a ética do "depende das circunstâncias", a negação da pobreza e a banalização da violência com discursos que apresentam as indignidades como justas, adequadas e inexoráveis.

Capitulam as utopias aos pés do metabolismo do capital absolutizado? É o fim das lutas dos que vivem do trabalho? A morte da perspectiva de construção de um novo modo de produção que origine relações sociais igualitárias como possibilidade histórica? Ou há espaços de contradição que permitam a construção coletiva de projetos contra-hegemônicos? Há muito que pesquisar!

Por isso tenho repetido aos meus alunos ao longo dos anos: a grande descoberta de cada pesquisa é que quanto mais se avança mais há a conhecer; quanto mais se pesquisa, maior a consciência do quanto não se sabe... e aí está o fascínio do ser pesquisador... um trabalho que nunca se conclui, que traz cada vez mais perguntas e que nos impulsiona a prosseguir... como certo, só a consciência dos limites, a clareza das opções epistemológicas e a virtuosidade das parcerias...

Pesquisar, ensinar, sentar de roda, discutir, concordar, divergir, buscar... vida que se renova a cada dia, e que vale a pena viver, porque sempre coletiva, sempre provocativa, sempre instigante...sempre insatisfatória...energia que nos move rumo às nossas utopias!

Obrigada a todos que têm, das mais variadas formas, compartilhado comigo dessa trajetória! Obrigada, Liz, por nossa grande família! Obrigada aos meus netos que, com sua alegria, renovam minhas energias a cada dia!

\section{REFERÊNCIAS}

FRIGOTTO, Gaudêncio. Estuturas e sujeitos: os fundamentos da relação entre trabalho e educação. In: SAVIANI, D.; SANFELICE, J.L.; LOMBARDI,J .C. (Org.). Capitalismo, 
trabalho e educação. 3. ed. Campinas: Autores Associados, 2005. p. 61 a 74.

KUENZER, Acacia Zeneida. Pedagogia da Fábrica. São Paulo: Cortez, 1985.

Ensino de 2. ${ }^{\circ}$ grau: o trabalho como princípio educativo. 3. ed. São Paulo: Cortez, 1997 a. v. 1. 166p.

Ensino Médio e Profissional: as politicas do Estado neoliberal. 1. ed. São Paulo: Cortez,

1997 b. v. 01. 104p.

. As políticas de formação: A constituição da identidade do professor sobrante. Educação e Sociedade, São Paulo, v. 1, n.68, p. 163-201, 1999.

Ensino Médio: construindo uma proposta para os que vivem do trabalho. 1. ed. São Paulo: Cortez, 2000. v. 1. 248p .

. Conhecimento e competências no trabalho e na escola. Boletim Técnico do SENAC, Rio de Janeiro, v. 28, n. 2, p. 3-11, 2002.

Competência como práxis: os dilemas da relação entre teoria e prática na educação dos trabalhadores. Boletim Técnico do SENAC, Rio de Janeiro, v. 29, n.1, p. 17-27, 2003.

. A formação de professores para a educação profissional. In: 12 ENDIPE, 2004, Curitiba. Conhecimento local, conhecimento universal, 2004.

. Exclusão includente e inclusão excludente: a nova forma de dualidade estrutural que objetiva as novas relações entre educação e trabalho. In: Dermeval Saviani; José Luiz Sanfelice; José Claudinei Lombardi. (Org.). Capitalismo, trabalho e educação. 2. ed. Campinas: Autores Associados, 2005 a, p. 77-96.

.; MORAES, Maria Célia Marcondes. Temas e tramas da pós-graduação em educação. Educação e Sociedade, Campinas, v. 26, n. 93, p. 1341-1362, 2005b.

. A educação profissional nos anos 2000: a dimensão subordinada das políticas de inclusão. Educação e Sociedade, v. 27, p. 877-910, 2006.

Da dualidade assumida à dualidade negada: o discurso da flexibilização justifica a inclusão excludente. Educação e Sociedade, v. 28, p. 1153-1178, 2007 a.

.; ABREU, Cláudia; GOMES, Cristiano. A articulação entre conhecimento tácito e inovação tecnológica: a 
função mediadora da educação. Revista Brasileira de Educação, v. 12, p. 1-16, 2007 c.

.; CALDAS, Andrea. Trabalho docente: comprometimento e desistência. A intensificação do trabalho docente: tecnologias e produtividade. 1. ed. Campinas: Papirus, 2009, v. 1, p. 19-38.

O Ensino Médio no Plano Nacional de Educação 2011-2020. Educação \& Sociedade, v. 112, p. 851-874, 2010.

MARX, Karl. O Capital, Livro 1. O processo de produção do Capital. São Paulo: Difusão Editorial, 1982, v. 1.

MARX, Karl; ENGELS, Friedrich. A ideologia alemã. Martin Claret, São Paulo, 2006. 